Article

\title{
Sociocultural Dimension of Land-Sea Interactions in Maritime Spatial Planning: Three Case Studies in the Baltic Sea Region
}

\author{
Tarmo Pikner ${ }^{1, *}$, Joanna Piwowarczyk ${ }^{2}$, Anda Ruskule ${ }^{3}$, Anu Printsmann ${ }^{1}{ }^{(\mathbb{C}}$, Kristīna Veidemane ${ }^{3} \mathbb{C}^{(}$, \\ Jacek Zaucha ${ }^{4,5}$, Ivo Vinogradovs 6 (i) and Hannes Palang ${ }^{1}$ (i)
}

Citation: Pikner, T.; Piwowarczyk, J.; Ruskule, A.; Printsmann, A.;

Veidemane, K.; Zaucha, J.;

Vinogradovs, I.; Palang, H.

Sociocultural Dimension of Land-Sea Interactions in Maritime Spatial Planning: Three Case Studies in the Baltic Sea Region. Sustainability 2022, 14, 2194. https://doi.org/10.3390/ su14042194

Academic Editors: Henning Sten Hansen and Lise Schrøder

Received: 25 November 2021 Accepted: 10 February 2022 Published: 15 February 2022

Publisher's Note: MDPI stays neutral with regard to jurisdictional claims in published maps and institutional affiliations.

Copyright: (c) 2022 by the authors. Licensee MDPI, Basel, Switzerland. This article is an open access article distributed under the terms and conditions of the Creative Commons Attribution (CC BY) license (https:// creativecommons.org/licenses/by/ $4.0 /)$.
1 Centre for Landscape and Culture, School of Humanities, Tallinn University, 10120 Tallinn, Estonia; anu.printsmann@tlu.ee (A.P.); hannes.palang@tlu.ee (H.P.)

2 Institute of Oceanology, Polish Academy of Sciences, 81-712 Sopot, Poland; piwowarczyk@iopan.gda.pl

3 Baltic Environmental Forum, 1010 Riga, Latvia; anda.ruskule@bef.lv (A.R.); kristina.veidemane@bef.lv (K.V.)

4 Faculty of Economics, University of Gdańsk, 81-824 Sopot, Poland; jacek.zaucha@ug.edu.pl

5 Maritime Institute, Gdynia Maritime University, 81-225 Gdynia, Poland

6 Department of Geography, University of Latvia, 1004 Riga, Latvia; ivo.vinogradovs@lu.lv

* Correspondence: tarmo.pikner@tlu.ee

\begin{abstract}
Spatial planning faces challenges in addressing interactions between land and sea. This paper elaborates on land-sea interfaces, which can integrate certain socio-cultural values and related tensions into maritime spatial planning (MSP). In this article, three regional case studies from Estonia, Latvia, and Poland analysed important intersections between the formations of cultural values and spatial dynamics within MSP processes. These cases make it possible to address current challenges, contested boundaries, and spatial planning possibilities to embrace the vibrant and complex ways the sea becomes connected to societal change. The study indicates the multiplicity of land-sea interfaces, which should be involved in MSP through situated places of terraqueous interactions, means of public participation, and meaningful boundaries within mobilised co-existence. The actual and possible tensions in allocating new functions of maritime spaces indicate the importance of coastal landscapes and communities. Thus, MSP practice can employ the land-sea interfaces to advance regional planning through participatory engagements, which reveal sociocultural linkages between society and environment on coastal areas.
\end{abstract}

Keywords: maritime space; land-sea interactions; coastal landscape; cultural values; maritime spatial planning; Baltic Sea

\section{Introduction and the Thematic Approach}

Tangible and intangible interactions between terra firma and the sea are crucially important in the planning of complex maritime spaces. The sociocultural dimension of these interactions has often become simplified, as linking marine environments and experienced landscapes in a holistic spatial planning process is complex. Purely shifting perspective from 'landscape' to 'seascape' seems to overlook aspects of relational interfaces between land and sea, which are simultaneously lived on the personal level and entangled with politics. Therefore, rethinking the interpretation of planning concepts and participatory dynamics is necessary to adequately address the contingent uses and values related to land-sea interactions. Coastal areas play an important role in facilitating and maintaining land-sea interactions, and there is a need "to engage critically and reflexively with the multi-scalar, regional embedding of the coast and the sea as sociocultural spaces and places" $^{\prime \prime}[1]$ (p. 10).

The aim of the paper is to understand the socio-cultural dimension of maritime spaces by focusing on land-sea interfaces in maritime spatial planning (MSP). This focus can highlight the various challenges in spatialising and integrating sociocultural land-sea interactions to MSP processes. The paper includes thematic coastal area related dynamics 
from three Baltic Sea-related cases, which indicate various possibilities, tensions, and participatory processes to integrate sociocultural values into MSP practice. Thus, the paper offers a novel perspective on the multiplicity of land-sea interfaces and the formation of shared values, which could be consistently elaborated within MSP processes.

The paper continues with the introduction of the theoretical approach, the second part describes the applied methods in the three cases, the third part presents the case-related findings, the fourth part elaborates the thematic discussion, and the fifth part presents conclusions.

MSP shapes marine spaces to achieve ecological, economic, and social objectives through political processes [2]. The dimension of decreasing social conflicts in MSP has become more explicit during the last decade. The recent UNESCO-IOC/European Commission guideline says that "MSP [formulated as marine/maritime spatial planning] is a comprehensive and strategic process to analyse and allocate the use of the sea areas to minimise conflicts between human activities and maximise benefits, while ensuring the resilience of marine ecosystems" [3] (p. 23). These guidelines articulate the importance of integrating terrestrial and maritime planning by providing coherence for territorial actions "especially for coastal areas themselves composed of land-sea interfaces". However, MSP as a practice entails complex processes do not necessarily relate directly to the institutional (state or region level) document of MSP Plan (later referred as Plan). By focusing on landsea interfaces, we can address "a gap concerning the ways in which we engage with seas and oceans with a will to inspire action and evoke change" towards taking seas seriously in understanding socio-cultural and political changes [4] (p. 1). MSP could ideally be the tool for reworking this gap towards the terraqueous space formed through "interfaces between worlds where land and water meet and mingle" forming the global coastline [5] (p. 108).

MSP's multiplicity and inherent (trans)boundary perspective can be accurately expressed in the term 'interface', as defined in the dictionary as: (i) the place at which independent and often unrelated systems meet and act on or communicate; (ii) the means by which interaction is achieved; (iii) a surface forming a common boundary of two bodies, spaces or phases [6]. Therefore, the land-sea interface embraces situated places of interaction, ways of engaging, and meaningful boundaries within mobilised co-existence with the sea. This kind of interface in spatial planning makes it possible to visualise and empower (meaningful) land-sea interactions. It is relevant that landscape studies have used the concept of landscape interfaces to bridge different oppositions, including those between knowledge cultures, culture and nature, past and future, and preservation and use, amongst others [7].

There is a landward bias in understanding territories and landscapes, and the sea is often treated as a blank canvas [8]. The remarkable intensification of the anthropogenic effect on the oceans has increased the need to address diverse spaces of co-existences between land and sea. The process of MSP formulates diverse boundaries and possible embedded usages in relation to seas and oceans in the long term. These dynamics of spatial planning co-exist with metageographies and spatial imaginaries that generate context for interactions between land and sea [1]. The role of land-sea interactions in MSP is stressed in recent studies [9-11]. Land-sea interfaces as terraqueous spaces are analysed, for example, in the context of the mobilised territoriality of adjacency rights for fishing shrimp [12] and terraqueous urbanism related to oil extraction [13]. However, employing MSP beyond such sector-based analysis is challenging. Interactions (and their absence) between land and sea, including sociocultural aspects of land-sea interfaces as places of terraqueous interactions, ways of participatory engagement, and meaningful boundaries of co-existence, should be important aspects of MSP, although it often has limited capacities to deal with this complex issue [14].

For example, the land-sea interface includes visual imagery and lived experiences that are not always accommodated (or disregarded) in MSP processes. The dimensions of land-sea interfaces are discursively and socially produced through boundaries that mediate complex relations between the sea, culture, and experienced landscapes. These kinds of 
dynamics can appear through 'soft spaces' [15,16] in (maritime) planning, which reach beyond conventional administrative boundaries, and are general enough to link concerns and shift some existing patterns of governance. Marine space loses its traditional character of the border (frontier) and becomes a contact point for various political, economic, and environmental interests [17].

The MSP framework poses high expectations of experimental planning but it is unknown how far MSP is capable of going beyond a sea-based remit to fully address land-sea interactions [14]. MSP borrows elements from terrestrial planning; therefore, reflections are needed about its spatial and participatory approaches $[18,19]$. The concept of zoning is applied in usages of land and sea, but in marine spaces, this requires elaborations due to "the inherent mobility of the sea, the contingency of human activities upon its dynamics, and the need for planning to embody the relational complexities of the sea itself and of human interaction with it" [20] (p. 521), see also [21]. This relational complexity has generated challenges for integrating socio-cultural values into the land-sea interfaces in MSP processes. Social science traditions of practical wisdom and reflexivity can provide valuable insights for understanding values and power dynamics, which shape future maritime spaces $[19,22]$.

The making and use of maps employ diverse embedded values and functions, thereby playing an important part in the spatialisation of the sea. In this, maps can produce reality as much as represent it [23], and mapping has become the explicit phase at which diverse actors and stakeholders must pass [24]. For example, land-sea interactions became framed as an issue of societal and cultural importance pertaining to the identity of the 'Dutch nation' and the policymakers have demonstrated a keen awareness of the performative power of visual imagery in North Sea 2050 Spatial Agenda [1]. Emergent maps and metaphors about the sea will produce ways of spatially structuring our perception, which has similar tendencies in the evolution of institutionalised regions generated by collective action $[25,26]$.

Developing a MSP practice often operates with spatially represented generalised data distanced from lived experiences and vernacular knowledge, and this leads to a tendency to reduce the sea's cultural values and functions [27-29]. However, cultural sense-making can be seen as an essential mechanism in operationalising marine spaces within enacted MSP practice. One of the most comprehensive definitions suggests that maritime culture is about the meanings people assign to the sea and their relations with this environment [27]. A narrower approach to defining maritime culture is the concept of maritime cultural heritage, which alongside tangible historical objects and landscapes includes intangible habits and practices passed on from generation to generation [30]. The cultural dimension and societal connections in maritime spaces are approached through diverse analytical frameworks, and the cultural ecosystem services (CES) approach has been elaborated further in addressing community-based narratives and culturally significant areas [31] and mapping communities at sea [32].

The generation of meanings bound to maritime spaces can be discussed through place-based attachments and landscapes. Although "since sea is not dwelled in in the usual sense of the word, it is theoretically conceivable that the capacity of the sea to turn into a place is inherently limited" [25] (p. 39). These differences about dwelling-in and spatial embeddedness generate challenges for understanding land-sea interfaces in forming meaningful (more-than-terrestrial) landscapes as "an area, as perceived by people, whose character is the result of the action and interaction of natural and/or human factors" [33] (p. 9). International MSP guidelines [3] include "seascape" as a concept to assess and characterise relationships between culture and natural environments informing settings for everyday life. Therefore, it is necessary to carefully situate 'coastal' and dispersed 'land-sea interactions' in the social construction of maritime spaces in MSP. Shores can be seen as dynamic interfaces between the politics of territorialisation and practices of solidarity relating to maritime spaces [34]. A coastal landscape can render visible the sociocultural dimension of land-sea interactions. For example, culture has multiple roles in socialising 
and spatialising maritime-based entities within communities of practice that contribute to the sustainability of coastal landscapes, e.g., small fisheries contribute to the maintenance of cultural landscapes [35]. The landscape is also recognised as an essential resource for coastal tourism development and boosting the local economy [36]. To summarise, the elaborated approach on the multiplicity of land-sea interfaces in MSP contributes to understanding complex spatialisation dynamics in (dis)integrating sociocultural values and marine spaces and coastal linkages. This approach to land-sea interfaces brings together places of interactions, means of participatory practice, and (contested) boundaries and time horizons. This approach contributes to the discussion of the gaps and potentials of MSP in achieving sustainable and socially accepted solutions.

\section{Materials and Methods: Three Cases}

The empirical cases come from three coastal areas of Estonia, Latvia, and Poland (Figure 1). These cases analysed the sociocultural dimension of land-sea interactions in MSP by focusing more specifically on certain interfaces, thereby highlighting and framing co-existences between land and sea. The institutional and cultural contexts that form MSP are different in these three countries of the Baltic Sea region. However, by presenting these cases, we can address current challenges, contested categorisations, and potentials in MSP for embracing vibrant and complex ways the sea is connected to everyday living and societal change. These three case studies include (but are not limited to) materials from the Interreg project called Land-Sea-Act. Much of the participatory processes during the project were affected by the COVID-19 outbreak, which meant a smaller number of people in face-to-face meetings or substitutions with online discussions, with their limitations. The paper does not look at the whole case studies per se but their interrelation with respective MSP dynamics.

The Estonian case (the central section of the northern coast) looks at how recent national MSP relates to regional sociocultural aspects of maritime spaces with a focus on coastal tourism and mobility. Desktop study of all relevant statistical information, spatial data, policy, and planning documents was carried out. The study also entailed a qualitative content analysis of national MSP documents and public protocols of MSP discussions. Four focus group interviews in respective municipalities revealed perspectives on the current initiatives and governance processes in coastal planning. In-depth interviews $(n=13)$ with managers of small-craft harbours and coastal village community members active in advancing tourism focused on values, practices, and tensions related to living with the sea. Based on this, four explanatory scenarios were created through participatory engagements (with 10 students, 27 local school children, 7 stakeholders) and tested on a representative sample of local inhabitants $(n=758)$ and blue economy stakeholders $(n=100)$ in the area along with other topics, such as maritime culture, blue economy challenges, developmental trade-offs, tourism, mobility issues, and multi-level co-operation.

The Latvian case (south-western Kurzeme) uses an ecosystem services (ES) approach for exploring trade-offs and possible solutions for balancing national interests for offshore wind park (OWP) development with local interests in promoting coastal tourism. The case study focuses on CES, including landscape qualities, although other ES are also mapped. Several methods are used, including: (i) biophysical mapping of land(sea)scape areas and assessment of ES provided by them [37] ; (ii) stakeholder engagement in the formulating of coastal development challenges and potentials through an interactive workshop (40 participants), an online survey of involved stakeholders $(n=31)$, and an online participatory Geographic Information Systems (GIS) survey on favourite recreational sites ( $n=80$ ) using ArcGIS Survey 123; (iii) scenario-building workshop (40 participants) using a target-seeking scenario (normative) method [38] for identification of alternative pathways (i.e., locations of the OWP) to reach national targets for renewable energy production; (iv) a nationwide public survey $(n=1000)$ to assess the contribution of the coastal nature areas of south-western Kurzeme to human well-being; (v) elaboration of optimal spatial solutions for offshore wind energy production and coastal tourism development. 


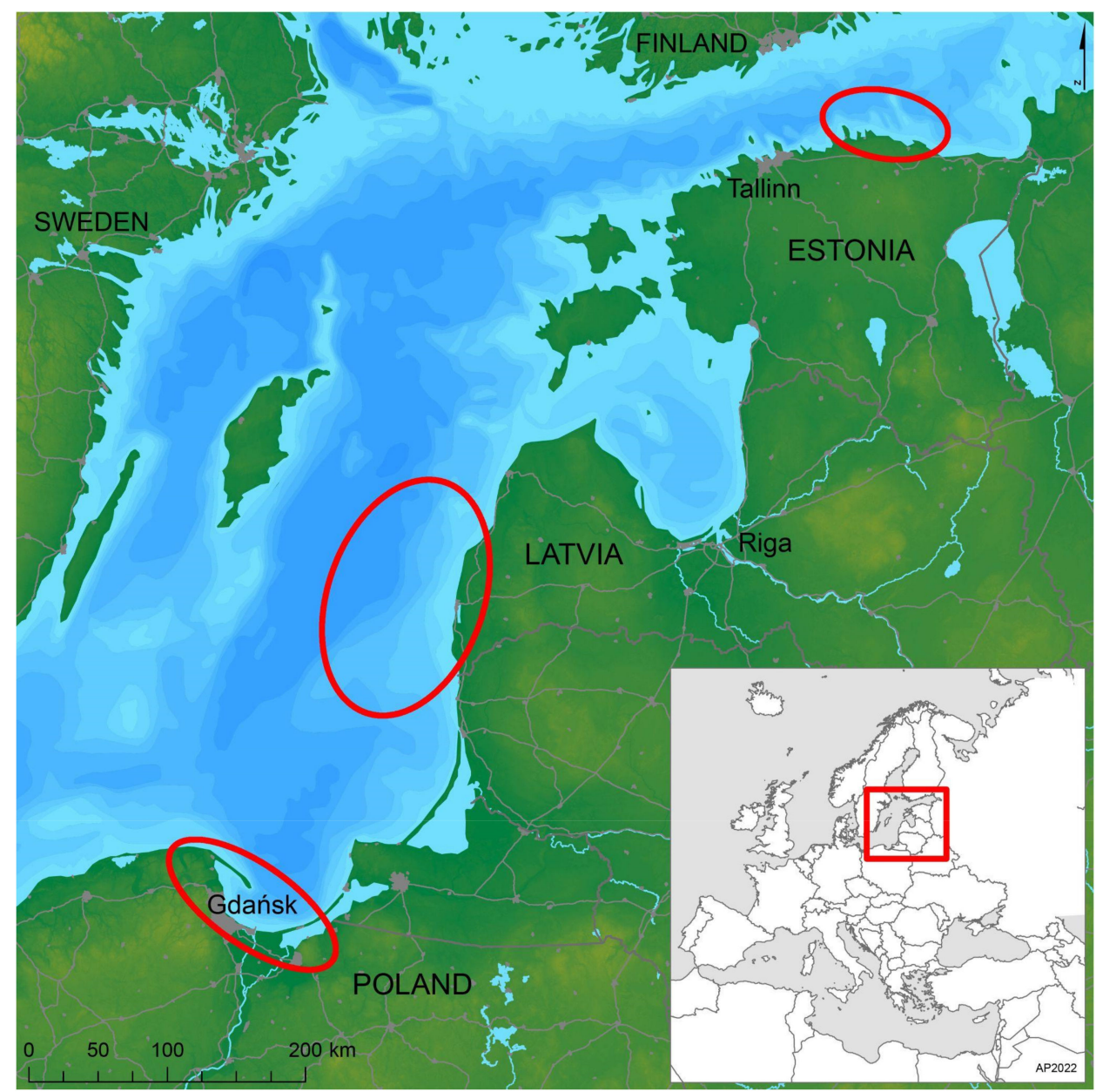

Figure 1. Locations of the case study areas (source: Land-Sea-Act project partners, GADM 2021, ESRI Media Kit 2006, EGCD 1998, GMTED 2010).

The Polish case (Gulf of Gdańsk) focuses on the participatory assessment of (intangible) cultural values, barriers, and solutions to transform towards more environmentally and culturally oriented tourism. This was implemented through a series of stakeholder interactions, including workshops and semi-structured interviews. The results presented in this study summarises the current level of cultural values in MSP. The results are based on the analysis of (i) resolutions of the MSP for all Polish marine areas, (ii) remarks submitted by various stakeholders concerning three MSPs (the Plan for the whole Polish marine areas, for the Gulf of Gdańsk, and the Vistula Lagoon), and (iii) an interactive workshop (14 participants) on cultural values run with maritime planners and marine experts.

\section{Results}

\subsection{The Estonian Case}

The first ever national strategic MSP (2035+) in Estonia will most probably be adopted in the beginning of 2022. This means that long-term use rights, co-existences, and boundaries will be drawn on state-owned marine spaces. This perspective contributes both to preserving the environment and advancing a sustainable blue economy [39]. The spatialisation of new maritime usages (renewable energy, aquaculture, infrastructure networks) causes tensions alongside the existing traditional uses and diverse (regulated) values. According to the national MSP co-ordinator, the Plan seems "hybrid" because it is strategically general and simultaneously gives spatialised guidelines for various fields of maritime usage.

The regional dimension in the state-level MSP appears through two (excluded) former pilot-regional plans, see also [22], the regional 'portraits' of maritime areas, and organising 
public feedback meetings. Altogether, 13 regional public stake-holder meetings were held to discuss the principles, impact assessment, and draft spatial solutions in the MSP process. These regional coastal portraits were formed through sociocultural mapping (conducted by the consultancy enterprise) including 38 object types covering valuable landscapes, infrastructure, cultural events, heritage sites, and marine practices (Figure 2). The mapping of maritime cultural values and regional portraits were integrated into the impact assessment process towards five generalised 'land-sea clusters' [40]. These clusters appeared as very broad regional fields of functional specialisation in tourism and blue economies, the maritime character of which could foster holistic development and achieve climate neutrality aims. However, the functional approach of culture within land-sea interactions falls mainly out of the state-level MSP scope of spatial planning. Maritime tourism and recreation are generally handled through compensation/additional measures and possible co-usages, in which the crucial planning role rests on local municipalities. The marine area is planned only by the state, and the municipal level of decision-making is involved in planning accessibility infrastructure to the seashore.

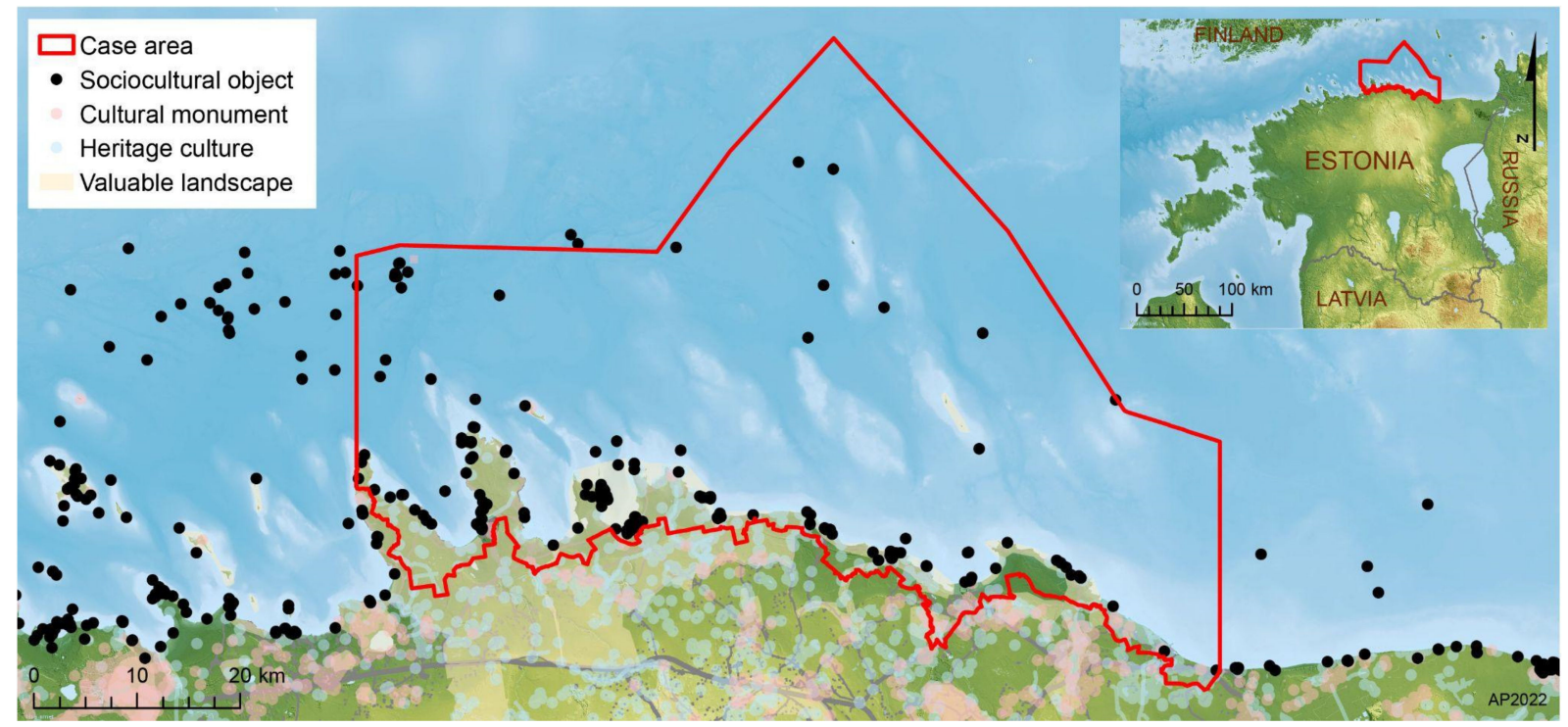

Figure 2. Different national value mappings in the Estonian case study area (source: Maritime Spatial Planning 2017, Heritage Board 2017, State Forest Management Centre 2017, Harju and Lääne-Viru counties 2017; base map: Estonian Land Board 2022).

The central section of the northern coast of Estonia contains mainly elements of coastal tourism, potential sea related connectivity links to Finland, and heritage aspects. The marine area of the case study contains significant regulatory spaces and guidelines related to the Lahemaa National Park and military training areas extending beyond land. Natural and cultural milieu preservation rationalities (see Figure 2) co-exist with the dynamics of seasonal tourism, urbanisation (second-home users), and semi-industrial small towns. The planning and maintenance of public accessibility nodes to seashore and small-craft harbours form important land-sea interfaces for maritime tourism and recreation. The Estonian MSP acknowledges these aspects but leaves them mostly untouched because of (b)ordered scales and frames of 'maritime' in spatial planning.

The maritime character of the current land-sea interactions is partly defined by Sovietera disturbances, where there were unmapped closed settlements in militarised coastal zones with few selected sites for leisure activities $[35,41]$. These rigid settings co-existed with the structural planning of recreational complexes for state enterprises and the establishing of summer houses in rural coastal areas since the 1960s [42]. Diverse boundaries of land restitution from the 1990s $[43,44]$ challenged the common rights of accessing the 
seashore and small landing sites rich in legacies often shared or maintained by one family (Figure 3).

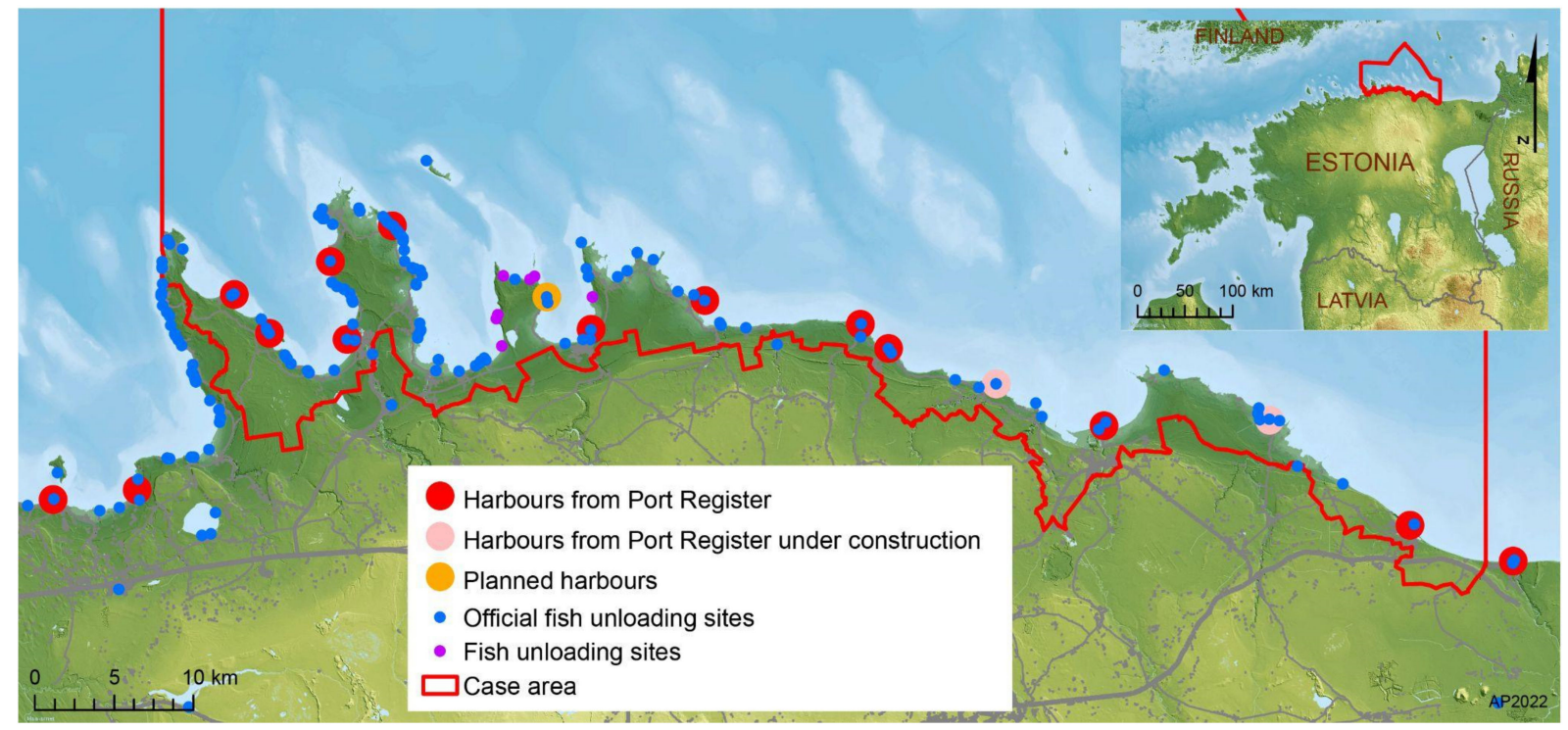

Figure 3. Small-craft harbours and landing sites (source: Port Register 2022, Ministry of Rural Affairs 2017, fieldwork interviews; base map: Estonian Land Board 2022).

MSP maps include existing harbours but will not directly regulate the planning of small harbours. Yet, there is an acknowledged need [40] to remake the classification of harbours and elaborate the existing harbour network (ideal distance 30 nautical miles) with the cultural services of surrounding settlements. The case study revealed the rationality to make the network of small-craft harbours more multifunctional. The interviews indicated that establishing or reconstructing small harbours could unite and also divide local communities. Most of the harbours are privately owned, and diverse aspects of social justice about access and the extent of expected transformations converge. The commodification (through tickets) of access to a formerly abandoned military harbour divides permanent residents from influential summer-home owners wanting to establish amenity landscapes over coastal countryside ideals. However, several small-craft harbours did enliven maritime culture by providing sailing lessons for school pupils, spaces for community initiatives and seasonal gastronomy, materialised infrastructure for sailing and fishing, and sites for representing coastal heritage.

The Estonian MSP states that the whole coastal marine space is culturally valuable, and the Plan would not explicitly formulate areas of maritime culture. Many cultural heritage objects are found within the existing protective frameworks (see Figure 2). In addition to existing nature and bird protection areas, there will be four new preservation areas of maritime archaeology findings in northern Estonian territorial waters. Specialists had to explain during a public hearing that the wrecks of ships are going to be displaced only in extraordinary conditions after proper studies, also when allocating the OWP. The workshop discussions indicated that this still extensively invisible heritage brings together enthusiastic international groups of divers and memory-political initiatives (e.g., Russian state-supported foundation searches for Soviet submarines) bound to dark maritime legacies in Estonian territorial waters.

The Estonian MSP is based on a wide ecosystems-based approach (including cumulative impacts), which appears through dozens of thematic studies and almost 40 maps in the public version of the Plan [39], and half of these maps are related to forming the suitable maritime spaces for OWP. The leading MSP expert highlights the mismatch of knowledge uses: policymakers operate with general terms while scientists work with specialised knowledge on a micro-scale, and an IT platform was needed to bridge these 
two. Furthermore, this scientific approach of combining existing data and extrapolating it generated critical comments in public MSP discussions about what counts as the 'best available knowledge' for making long-term strategic decisions about marine space usages.

The porosity of marine space appears in planning through (possible) co-existing usages. The MSP has partly resulted in delimiting areas of co-usage, which also has its perils—-tackled in the impact assessment [40] — because of uncertainties inherent in predicting the trajectories of technological change (e.g., the height of wind turbines came up during the public hearing). The larger tensions between trawl fisheries and OWP planning required strategic decisions from the government. The OWP-related tensions motivated the development of methodological guiding material to assess the visual impact of an OWP, which could be further used by coastal municipalities. Most of the activity spaces for 'blue growth' (especially OWPs) are foreseen for the western coast of Estonia with its two large islands and more favourable shallow sea. The zoning of targeted marine spaces was seen as a tool to support the porosity of integrated practice within fluid terrains.

The case study indicates that co-usages of maritime spaces evolve in time and can also generate tensions between interest groups. The mapping of heritage did reveal culturally rich historic paths along the coast, but village inhabitants did not always welcome harnessing these legacies for tourism development because of the expected invasion of visitors. Water sport activities can cause problems for coastal fishermen, and there was support for establishing clear boundaries for riders of sea scooters. The local municipality became concerned about the impact (noise, visual disturbances) of new military protection areas indicated in the MSP and requested further studies. From the survey, it was clear that the local inhabitants and blue economy stakeholders favoured small-scale development respectful of maritime culture to increase mass tourism and accelerate the blue economy. When it comes to promoting coastal tourism and mobility, no massive investments are needed to develop hiking trails, services at the small-craft harbours, nature observations, and beach infrastructure and parking. Accommodation and fishing opportunities may require more strategic actions. Culture, gastronomy, entertainment, and tourist information were also mentioned in the top 10 out of a list of 19 proposed activities. The coastal municipalities were interested in exercising the planning power of marine space to one nautical mile but also hesitant because small municipalities lack of thematic planning skills, see also [45].

\subsection{The Latvian Case}

The first national MSP Plan of Latvia was approved by the government in May 2019. The Plan is declared as a long-term (to 2030) spatial development planning document that defines the use of the sea by considering the terrestrial part that is functionally interlinked with the sea and coordinating the interests of various sectors and local governments [46]. In addition to existing legally binding conditions for the use of the sea, the Plan defines marine areas with priority use for shipping, military interests, investigation of natural values, research areas for OWP development, and corridors for prospective electricity cables. The priority uses of the marine space are defined by excluding or setting restrictions on other activities which may hinder the existence or development of the prioritised use. The Plan is a strategic policy document and by its legal status non-binding to third parties (e.g., economic players, municipalities, NGOs, citizens); however, it is imperative for state authorities in licencing or planning processes within marine waters. The Plan sets conditions regarding activities in the areas of priority use-the Ministry of Economics may issue licences for the installation of OWPs only in the designated research areas for OWPs. The conditions set by the Plan also include restrictions on stationary constructions to ensure safe navigation in areas reserved for shipping or military interest.

Land-sea interactions in the Latvian Plan are embedded by one of its strategic objectives: integrated use of marine and terrestrial areas by promoting the development of maritime-related businesses and the required infrastructure. The specific tasks of this objective relate to harbour development and coastal protection against erosion and climate 
change impacts. The Plan analyses port development trends and needs, feasibility for connecting underwater electricity cables from OWPs to onshore grid networks, landing sites for coastal fishery, maritime cultural heritage, landscape, as well as tourism and recreational activities at sea and their functional linkage to the land. However, the adopted Plan does not prioritise areas for coastal tourism development. This aspect is designated to terrestrial planning documents, including the National Long Term Thematic Plan for Development of the Coastal Public Infrastructure [47] adopted in 2016, as well as local municipal development and spatial plans. Since 2016, Latvian coastal municipalities have a right to plan the use of the sea up to two kilometres from the coastline; however, this opportunity is not yet commonly practised. Consequently, a true interaction between maritime and terrestrial planning, that would also cover important aspects of coastal community lifestyle, including tourism and recreation, is not yet well established.

Priority areas for the OWP development in the Latvian Plan were identified mostly based on a set of exclusion criteria such as compliance with existing regulations, avoiding areas that contain incompatible uses (e.g., intensive or regular shipping routes), the suitability of natural and physical conditions (e.g., limiting depth for installation of wind turbines), and technological capabilities (e.g., possibilities for connection with onshore electricity transmission grids). Although the potential negative impacts of OWP on coastal landscapes and ecosystems have been acknowledged in the Plan, this aspect was not fully considered as a decision-support criterion for defining the spatial allocation of research areas for the OWP development. Even stakeholder consultations organised while drafting the Plan confirmed that coastal residents oppose the siting of wind parks within a visible distance and the draft Plan proposed a distance of at least $20 \mathrm{~km}$ from the coastline as essential criteria for identifying suitable areas for OWP [48]. However, this was not endorsed during the final stage of the adoption of the Latvian Plan. Instead, the adopted Plan foresees that impacts on landscape as well as nature assets shall be assessed when issuing licences for the wind park developments; therefore, negotiation on balancing the interests of OWP and landscape protection is unresolved.

The Latvian National Long Term Thematic Plan for Development of the Coastal Public Infrastructure [47] highlights the landscape as an essential resource for tourism development. Following the concept of holistic tourism system performance, tourism destinations are characterised by such key elements as place attraction formed by the physical environment and landscape, access, amenities, and ancillary services [49]. This formed the conceptual basis for assessing the CES suitability of coastal areas for marine tourism and leisure during the first MSP [50]. The adopted Latvian Plan does not regulate coastal landscape protection and management but foresees that the values of coastal landscapes and potential impacts of different sea uses shall be assessed through detailed landscape studies at the level of coastal municipalities, while the assessment of underwater landscapes shall be linked to further biodiversity research in marine areas.

Mapping values of CES in coastal landscapes can be used to assess development trade-offs and support more sustainable sea/land use solutions [51]. This approach was followed by the Land-Sea-Act case study of south-western Kurzeme, Latvia, which aimed to develop proposals for balancing the national interest in OWP development with that of local communities in preserving the landscape and boosting coastal tourism and recreation. For that purpose, multiple values of terrestrial landscapes were assessed by applying the ES approach. The spatiality of ecological and sociocultural values was addressed by linking the assessment to landscape and seascape areas identified based on relatively homogenous biophysical (relief, geology, land cover, or habitat type) and use characteristics as service providing units. Landscapes are recognised as basic spatial units suitable for communication in planning and research [52], for mapping ES [53], and for defining landscape quality objectives [54]. Identifying such landscape/seascape areas also involves recognising place identity and cultural heritage and highlighting land-sea interactions. The lack of a spatial embeddedness ('scaping') of seascapes adjacent to the shore was 
addressed by mapping them in greater detail and assessing their qualities in connection with onshore landscapes.

Mapping of CES, including recreational potential, is often based on physical attributes [55]. This approach also included biophysical mapping and assessment of landscape qualities (aesthetic quality, uniqueness, diversity, naturalness, cultural heritage, and recreational potential) and other ES based on a list of indicators and analysis of spatial data sets and field observations. At the same time, participatory mapping methods make it possible to incorporate people's experiences and perceptions and to capture the plurality of CES values [56]. The case study applied participatory methods, including an online GIS survey for the identification of favourite recreational sites in the case study area and the types of activities for which they are used. Stakeholders were also involved in the assessment of landscape qualities with help of online tools during the interactive workshop. These methods allowed local knowledge to be collected to articulate the CES values in the case study area as well as served as verification of the expert-based biophysical mapping results.

The results of the case study, including the biophysical and participatory mapping of ES, were published online via Land-Sea-Act Map Explorer (see https:/ / www.bef.lv / projekti/land--sea-act-en/, accessed on 1 December 2021). The mapping reveals that higher CES values are mostly in the landscape areas near the coast, which overlap with the preferred sites for recreation collected using the participatory GIS survey. This confirms that high CES value is not only related to the outstanding natural beauty of landscapes and seascapes, but also to the opportunity to have physical interaction and experiences (e.g., traditional bathing, various water sports, including diving, wind- and kitesurfing, long-distance walks). Being in nature became even more recognised during the pandemic situation in 2020 and 2021, when indoor group activities were restricted. Analysis of the spatial distribution of the different ES indicated a trade-off between the naturalness of the landscape (associated also with higher supply of regulating services) and its aesthetic value as well as recreational potential. However, results of the nationwide public survey disclosed that most respondents would prefer "wild beaches" without amenities for recreation, which highlights the importance of preserving natural areas also as a resource for recreation.

Mapping and assessment of CES allow taking into account land-sea interactions in the planning process, in situations where developments in a fluid marine environment (e.g., installing OWP) is changing certain perceived and experienced coastal landscape qualities and related CES. In the Latvian MSP, the research areas for OWP development were delineated partly in the visibility zone of the shoreline stretches and inland landscape units of high landscape and recreational value. The expected impact of OWPs on landscape and tourism was highlighted as the main challenge for balanced coastal development at the Land-Sea-Act stakeholder meetings. During the scenario building workshop, stakeholders identified alternative pathways to achieve the ambitious targets for offshore wind energy production at the same time respecting the limitations set by the national Plan, the case study results of the ES assessment and other ecological values. The spatial alternatives were assessed in relation to their impacts on ES supply and the landscape and used to elaborate the optimal solutions for the OWP development by 2030 and 2050 (Figure 4). 


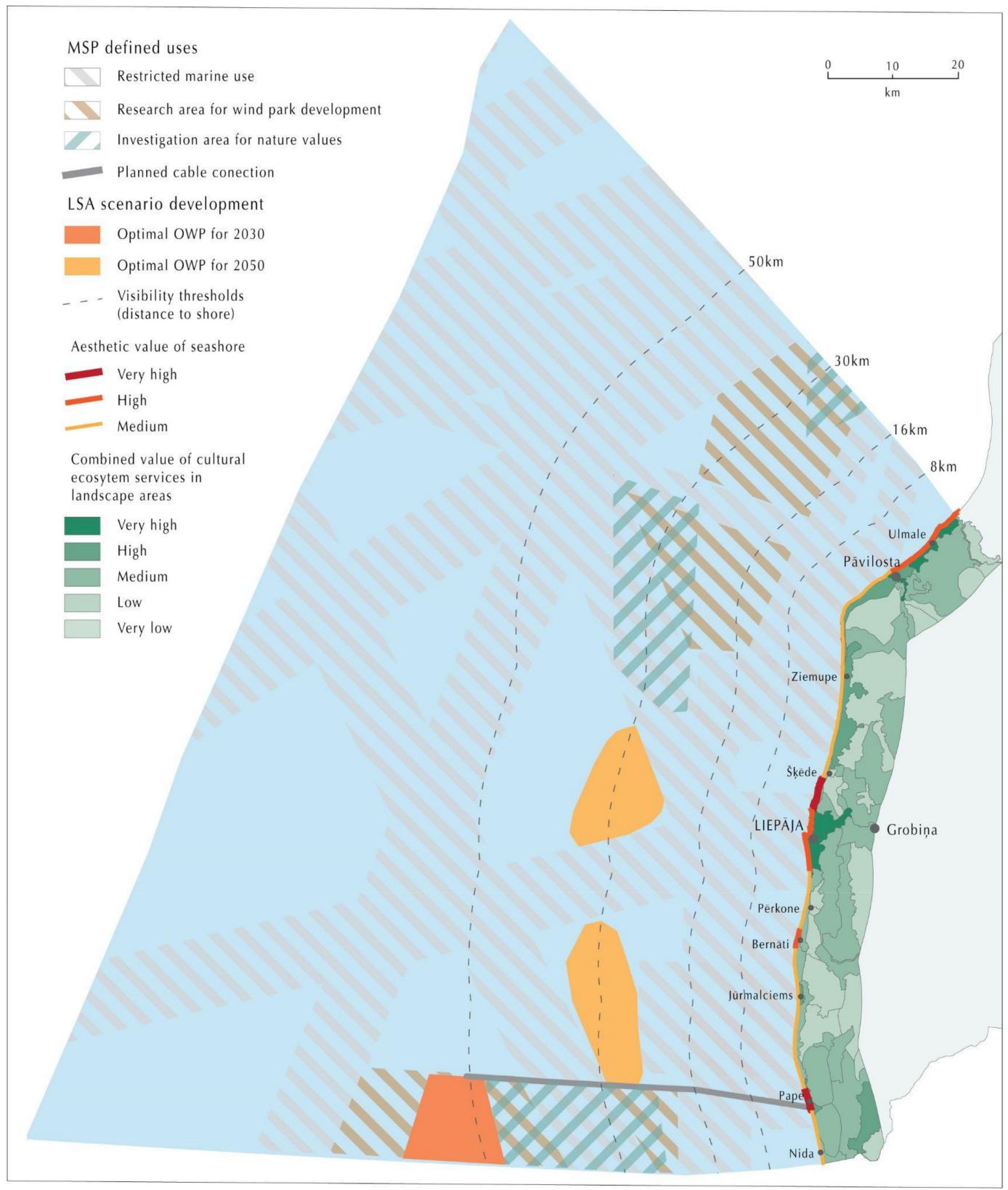

Figure 4. Results of the Latvian case: combined value of cultural ecosystem services of the inland and shoreline landscape areas; proposed optimal solutions of the offshore wind energy production by 2030 and 2050 .

\subsection{The Polish Case}

The MSP in Poland is a work in progress. The largest completed work is the Plan for all Polish marine areas (at a 1:200,000 scale) prepared in the years 2017-2019 and accepted in 2021. This Plan is substantiated by smaller more detailed plans prepared for the areas with a high intensity of spatial conflicts, such as lagoons, coastal areas, or ports. Out of all these plans, the most relevant ones for the Polish case study are the plans for the Gulf of Gdańsk and for the Vistula Lagoon, which are still under preparation.

The MSP is a managerial and political instrument that is expected to address ecology, economy, and society [2] in a given marine area and often in the adjacent land. Given this definition and the complexity of marine space [17], culture should be an essential part of any MSP; yet this is often not the case worldwide [27] and in Poland. Part of the problem is that maritime culture is a broad notion, and there is no single or well-defined way to approach 
it in MSP practice [27]. Like wider MSP tendencies to diminish the sea's cultural values, e.g., $[27,29]$, MSP processes in Poland have reduced maritime culture to tangible underwater cultural heritage, mainly wrecks. Even the concept of paleo-landscapes has only received some attention recently in the Gulf of Gdańsk MSP proceedings (2020-2021), based on the BalticRIM (Baltic Sea Region Integrated Maritime Cultural Heritage Management; https: / / www.submariner-network.eu/what-we-do/projects?id=970, accessed on 1 December 2021) project findings. As only one stakeholder mentioned it in the public consultation, it is uncertain whether the final Plan will consider these submerged landscapes from the Stone Age/Holocene. Other stakeholders have raised concerns about various maritime cultural elements, such as natural and cultural landscapes or historical objects. However, they were formally considered (and classified) as parts of other planning functions-'tourism' or 'nature conservation' - adding fragmentation to the management of cultural values in MSP.

Moreover, some calls for the protection of cultural objects and landscapes (e.g., concerning lighthouses) were rejected on the premise that they are outside the scope of the MSP. Indeed, one of the most critical issues in the Polish MSP is that it covers only marine areas but disregards land-sea interactions, which are especially important for maritime culture. It is an essential challenge for future MSP processes to define how maritime spatial plans should approach various cultural values outside their legal jurisdiction. This challenge is crucial for the MSP of coastal areas, where local and traditional communities tend to develop tighter bonds with the environment. This might be particularly relevant for coastal fishers in the Gulf of Gdańsk. Their intense feelings of local identity and marine ownership were visible during previous marine-related managerial initiatives, e.g., [57].

Limited jurisdiction is not the only challenge in properly embracing cultural heritage in MSP. Even if underwater maritime heritage is defined narrowly (i.e., as material objects), there is still limited knowledge of where such objects are. Further revisions of the Plan will require their systematic mapping beyond the few areas where such mapping has already been done. Perhaps because of this data scarcity, the actual plan for all Polish marine areas does not provide many detailed provisions concerning the management and protection of underwater heritage. It stipulates that any activities undertaken in Polish marine areas should not negatively affect identified (and existing) underwater heritage. Similarly, according to the precautionary principle, the same restrictions should apply to newly discovered objects of historical value. Archaeological inventory should precede any investments that may potentially affect cultural heritage. Further specific limitations stipulate, for example, that towed or fixed fishing gear cannot be used in places with recognised underwater cultural heritage. However, the Plan leaves significant flexibility concerning when or how to protect such heritage. Although the Plan advises protection in situ, the maritime administration can issue a permit to excavate the historical object from the sea to consider vital interests, such as the development of ports or nuclear power plants. For some places, the maritime administration maintains the right to introduce more specific restrictions if deemed necessary.

The absence of quality data is not limited to underwater heritage but is even more critical for intangible values. As discussed above, they are insufficiently recognised in the Polish MSP process and consequently by the Plan. Their protection is often viewed as irrelevant for the MSP as they involve terrestrial elements. Some hopes for an expanded perspective remain for the newly started (late 2020) MSP. The Vistula Lagoon inventory treated maritime cultural heritage very broadly regardless of location at sea or land. This gives some hope but still it will not solve the problem of the lack of relevant data on such intangible items as 'intimate connections' [58] and the lack of well-established routines for the collection of such data. During a project workshop on cultural values, both planners and marine experts showed an awareness that these values are not limited to wrecks and historical sites. They were able to identify and describe the sea's contribution to traditional craft, art, and local traditions, including the Kashubian language. However, they were much less confident about whether-and perhaps more importantly, how-these cultural values could (and should) become part of MSP. 
The workshop participants pointed out that such data are somewhat subjective and lack, in general, a spatial dimension; hence, they are not applicable in spatial management. This issue, however, does not apply exclusively to cultural values. Various data and information from stakeholders and even from scientific research (e.g., fishing grounds of artisanal fishery, sailing routes for leisure boats, or use of the sea by highly mobile marine species such as ichthyofauna and sea mammals) face similar challenges [59]. Even though methods for translating qualitative data into spatial representations, e.g., [27,31] exist, the planners will have to build the capacity to run and use these methods. Similar challenges in the Polish context referred to stakeholder involvement. The social actors need to understand how their 'values' and their 'perceptions' of the sea could be impacted by the MSP solutions, see also [60]. For instance, the research demonstrated that many stakeholders show a high appreciation towards places and views they enjoy in their daily lives but do not feel that MSP can protect (or alter) them. Hence, they do not participate in the relevant proceedings or limit their participation to the economy of their respective sectors. Therefore, both the planners and the stakeholders should learn together how to map such places of cultural importance and how to provide them with spatial delineations in the context of MSP.

\section{Discussion: Sociocultural Values Related Land-Sea Interfaces in MSP}

In terms of their relation to MSP, the three cases show that societal concerns appear as a constituting feature in forming maritime spaces through projections of boundaries and possible usages on the seas. The three cases addressed tensions and generated some suggestions for elaborating on the sociocultural dimension of land-sea interactions in MSP (see Table 1). The tensions bound to coastal tourism and cultural values of maritime spaces did appear in all cases. Some cultural values (e.g., underwater heritage) and potential conflicts between functions of maritime spaces were made publicly explicit. Challenges remain for empowering stakeholders in MSP to use participatory processes and visualisation of sea embedded connections. The scenario-based analysis integrated with stakeholder meetings can indicate values and meaningful places in the coastal areas, which influence perceptions and reveal possible conflicts emerging in MSP.

The cases point to the following multiplicity of land-sea interfaces in MSP and the ways these interfaces are entangled with sociocultural dimensions of coastal areas. Firstly, coastal areas provide dynamic environments in which everyday living practice with the sea takes place. The aims of terrestrial planning and of maritime planning meet within the shared coastal territory between the two planning regimes. Secondly, the land-sea interactions are achieved through diverse infrastructure, mobilities and cultural practice. On the other hand, these interactions in MSP are articulated through various communicative means, which include participatory mappings, scenario building, and wider stakeholder engagements. The tensions between tangible and intangible elements of maritime culture in MSP can appear and be addressed. Thirdly, land-sea interfaces are part of forming common boundaries between values and functions of maritime spaces. These boundaries relate also with nature-culture relations and with the time horizons of change by linking the past with future developments, e.g., climate change adaptations in MSP.

The current study indicates the 'coastal' as a particular and dispersed character linking marine environments and sociocultural dimensions within MSP. Thus, land-sea interface(s) in MSP "presents an opportunity to reground regional planning through substantive engagement with the materiality of society-environment relations on the coast" ${ }^{\prime \prime}[1]$ (p. 10). The 'coastal' is also merged in the process of defining the scope of MSP and its relevant land-sea interactions, for example, linking lighthouses more to the land than maritime spaces in the Polish case. Therefore, a stretch of coastal character within maritime space is usually ambivalent, spatially dispersed, and socially constructed. One option in MSP is to decentralise or fuse the 'coastal' directly into the wider maritime space. However, the studied processes show that coastal qualities or landscapes can reveal culturally situated land-sea interfaces and associated meanings through heritage and lively engagements 
with the sea. Therefore, more work is needed to elaborate the holistic approach on sociocultural dimension of land-sea interfaces in MSP, which integrate more-than-terrestrial spaces [16,61], dimensions of landscape care [62,63], and place-based perspectives on seas [25].

Table 1. Tensions and suggestions related to land-sea interfaces in maritime spatial planning.

\section{Articulated Tensions Related to Sociocultural Dimensions of Maritime Spaces}

(1) Co-existences and tensions between landscape nature-culture heritage and

Estonia,

the central section of northern coast
(2) Balancing different means of accessibility and mobilities (e.g., small harbours and coastal landing sites) related to coastal and marine spaces.

\section{Suggestions for Elaborating Land-Sea} Interfaces in Maritime Spatial Plannig

Bridging the gap between local values and national level planning through a regional approach, as also the 'clusters' showed different inclinations. To strengthen the capacities in communicating between municipalities and various stakeholders.

The importance of participatory mapping and visualisations to make culture-based linkages between land and sea explicit.

Need for engaging frameworks and initiatives supporting sustainable and community-based entrepreneurship.

To use the ecosystem service approach and assessment of landscape qualities (involving participatory methods) for highlighting the areas of high cultural value, revealing the development trade-offs and potentials for balancing different interests. Thematic plans can be used as an instrument to take cultural values into account in the governance of the coastal areas.

To improve co-operation and co-ordination among municipalities, state authorities and entrepreneurs in order to support sustainable coastal tourism development.

Develop, test, and validate tools and instruments that would allow for establishing standardised approaches to cultural values that could be easily adopted and used by maritime spatial planners. In the context of cultural values for MSP, more fully embrace land-sea interactions either in the form of formal regulations or soft guidelines. Explicitly articulate the (intangible) cultural values of marine environments. To discuss these values among the planners and the stakeholders together with their data and knowledge since these two groups do not recognise properly each other needs. Implement a pre-planning phase (or even pre-pre planning phase) to allow the stakeholders to be a part of MSP conceptualization, see also [28]. (Increasing the trust between stakeholders and planners needs to dedicate more time for planning processes, and therefore pre-planning phase is important as well.

There is a need to approach MSP as a process that is not completed and fixed in a document [64], because the MSP dynamics analysed in the cases did draw wider sketches of maritime spaces by leaving options open for more detailed spatialisation in allocating long-term usages. The evolution of maritime space depends on dispersed interrelations 
between public choice outcomes and markets [17], and diverse European Union (EU) and national frameworks have become part of these interrelations. For example, the dynamics of forming spaces for OWPs in Estonian and Latvian MSP rendered visible complex intersections between cultural values and wider climate-neutrality aims. The projected values and possible usages of shared maritime space indicate the porosity of land-sea interfaces, which appear in terms of ambivalent boundaries and ambitious plans for renewable energy production. This kind of porosity leaves some tensions unsolved in MSP and brings them to the next phase and level of spatial planning. These two countries also lack the advanced multi-level processes in MSP and significant power is dedicated on the national level instead of incorporating regional sub-plans.

The cases reveal the importance of carefully addressing the sociocultural aspects of land-sea interfaces in MSP. The linking of cultural values on coastal areas and MSP appears in the planning principles, but it is actually difficult to achieve in formulating national-level Plans.

In the studied cases, different approaches to translating culture and cultural heritage into MSP are evident. In this perspective, the Estonian Plan has conducted mapping of culturally significant coastal infrastructure and sites (see Figure 2), but the ways these spatialised meanings of the sea become part of planned maritime functions remain open. Sociocultural values are often rendered visible through tangible objects (more explicit in Polish MSP) such as underwater wrecks, and there are challenges in integrating intangible aspects of culture and new spatialised usages of marine areas in MSP. Latvian state-level MSP includes unresolved impacts of OWPs, and the possible tensions with landscape and tourism are expected to be addressed by the environmental impact assessment of the OWPs and licensing procedure. On the other hand, Latvia has elaborated the national thematic plan of coastal public infrastructure and allocated the sea planning rights to coastal municipalities up to $2 \mathrm{~km}$ from the shoreline. Maps and mappings appear as vital entities with potential and limitations in visualising culturally situated stories and affinities. Sociocultural aspects of land-sea interfaces became analysed on the local level but there are difficulties in scaling up to the national level and generating inter-scalar frameworks [28,31]. Therefore, it is critical to find ways to bridge how diverse stakeholders form meanings and planners rationalise ideas of culture and of place across marine and terrestrial boundaries.

Linkages between land and sea are cross-border in character and require 'one space' perspectives linking national terrestrial and marine territory and transcending national boundaries [14]. However, the case studies indicate that the conditions for applying this perspective differ between EU states because the rights of maritime planning are shared differently across the institutional levels. The scale and abstraction of maritime spaces in MSP become similarly important in producing macro-regions across the Baltic Sea. The land-sea interfaces within MSP dynamics influence how seas emerge in relation to existing regions and institutionalised borders. However, this indicates the contingency of spatial entities and their disappearance when they are no longer reproduced by society [25].

\section{Conclusions}

The paper contributed to understanding the sociocultural dimensions of maritime space by focusing on the multiplicity of land-sea interfaces in MSP. The three case studies in the Baltic Sea region indicate that land-sea interfaces in MSP are related to situated places of terraqueous interactions, means of public participation, and meaningful boundaries within mobilised co-existence with the sea. This perspective provides some tools for further elaborating the urgent need to address land-sea interactions in long-term MSP. The interfaces mobilised in MSP processes should be linked to the complex and emotional ways of living with the sea, often exceeding spatial presentations, but this does not mean that land-sea interfaces have become an unnecessary burden. The elaborated land-sea interfaces are important ways to bridge a gap between lively affinities and transformative changes in making the sociocultural values of maritime spaces publicly explicit in MSP processes. The dichotomies between land and sea in spatial planning can be challenged 
and reworked by giving more rights to the local level in planning for near-shore maritime spaces. However, this would differ based on institutional and historical dependencies and require further empowering of coastal stakeholders.

The analysed cases indicate actual and possible tensions in allocating new functions of maritime spaces. These tensions or even conflicts raise the importance of coastal landscapes and communities in wider sustainability transitions. Therefore, the land-sea interfaces in MSP have an opportunity to advance regional planning through participatory engagements, which reveal sociocultural linkages between society and environment in coastal areas. The visualisation and maritime boundaries appear as part of land-sea interfaces, which have capacities influencing public awareness and new maritime functions in MSP. Using culture to construct maritime spaces has two dimensions: longue durée values and dynamic changes in situated emotional experiences. MSP should meet the challenge of considering both these dimensions. Therefore, approaches and experimental frameworks towards bridging socioculturally embedded meanings and spatial planning representations in MSP are necessary.

Author Contributions: Conceptualization, T.P., J.P. and A.R.; Investigation, T.P., J.P., A.R., A.P. and K.V.; Methodology, T.P., J.P., A.R., A.P., K.V. and I.V.; Writing-original draft, T.P., J.P., A.R., A.P., K.V., J.Z., I.V. and H.P. Writing-review and editing, T.P. and A.P. Visualization, A.P. and A.R. All authors have read and agreed to the published version of the manuscript.

Funding: INTERREG BSR: \#R098 Land-Sea-Act; Polish Minister of Science and Higher Education: 5063/INTERREG BSR/19/2020/2; Estonian Research Council: PRG398.

Institutional Review Board Statement: Not applicable.

Informed Consent Statement: Not applicable.

Data Availability Statement: Spatial data are available publicly from the GADM (https://gadm. org) (10 January 2022); ESRI Media Kit CD-set (10 January 2022); Eesti Geograafia CD (http:// www.geo.ut.ee/kooligeo/egcd.php3) (10 January 2022); GMTED (https: / / www.usgs.gov / coastalchanges-and-impacts/gmted2010) (10 January 2022); Estonian Maritime Spatial Plan (https:// mereala.hendrikson.ee/uuringud.html\#) (11 January 2022); National Registry of Cultural Monuments (https:/ / register.muinas.ee/public.php?lang=et) (11 January 2022); State Forest Management Centre (https:/ / xgis.maaamet.ee/xgis2/page/app/parandkultuur) (11 January 2022); Harju county (https:/ / www.harjumaa.ee) (14 March 2017); Lääne-Viru county (https:/ / www.laanevirumaa.ee) (2 March 2017); Estonian Land Board (https://geoportaal.maaamet.ee) (11 January 2022); Port Register (https: / / www.sadamaregister.ee) (13 January 2022); and Ministry of Rural Affairs (https: / / www.agri.ee/sites/default/files/content/kalandus/lossimiskohad-2016-03-04.ods) (11 December 2017).

Conflicts of Interest: The authors declare no conflict of interest.

\section{References}

1. Walsh, G. Transcending land-sea dichotomies through strategic spatial planning. Reg. Stud. 2020, 55, 818-830. [CrossRef]

2. Ehler, C.; Douvere, F. Marine spatial planning: A step-by-step approach toward ecosystem-based management. In IOC Manual and Guides No. 53, ICAM Dossier No. 6.; UNESCO, Intergovernmental Oceanographic Commission and Man and the Biosphere Programme: Paris, France, 2009.

3. UNESCO-IOC/European Commission. MSPglobal International Guide for Marine/Maritime Spatial Planning; IOC Manuals and Guides No. 89; UNESCO: Paris, France, 2021.

4. $\quad$ Brown, M.; Peters, K. Introduction. In Living with the Sea: Knowledge, Awareness and Action; Brown, M., Peters, K., Eds.; Routledge: London, UK, 2019; pp. 1-12.

5. Hardenberg, W.G. Knowing the littoral: Perception and representation of terraqueous spaces in a global perspective. Isis 2021, 112, 108-110. [CrossRef]

6. Merriam Webster Dictionary. Interface. 2021. Available online: https://www.merriam-webster.com/dictionary/interface (accessed on 15 November 2021).

7. Palang, H.; Fry, G. Landscape interfaces. In Landscape Interfaces: Cultural Heritage in Changing Landscapes; Palang, H., Fry, G., Eds.; Kluwer: Dordrecht, The Netherlands, 2003; pp. 1-17.

8. Steinberg, P.; Peters, K. Wet Ontologies, Fluid Spaces: Giving Depth to Volume through Oceanic Thinking. Environ. Plan. D Soc. Space 2015, 33, 247-264. [CrossRef] 
9. Hietala, R.; Ijäs, A.; Pikner, T.; Kull, A.; Printsmann, A.; Kuusik, M.; Fagerholm, N.; Vihervaara, P.; Nordström, P.; Kostamo, K. Data integration and participatory process in developing integrated coastal zone management (ICZM) in the northern Baltic Sea. J. Coast. Conserv. 2021, 25, 47. [CrossRef]

10. Singh, G.G.; Cottrell, R.S.; Eddy, T.D.; Cisneros-Montemayor, A.M. Governing the Land-Sea Interface to Achieve Sustainable Coastal Development. Front. Mar. Sci. 2021, 8, 709947. [CrossRef]

11. Stancheva, M.; Stanchev, H.; Young, R.; Parlichev, G. Coastal erosion driven Land-Sea Interactions in Maritime Spatial PlanningA case of Bulgaria. J. Coast. Conserv. 2021, 25, 1-19. [CrossRef]

12. Foley, P.; Mather, C. Ocean grabbing, terraqueous territoriality and social development. Territ. Politics Gov. 2019, 7, 297-315. [CrossRef]

13. Chalfin, B. On-shore, off-shore Takoradi: Terraqueous urbanism, logistics, and oil governance in Ghana. Environ. Plan. D Soc. Space 2019, 37, 814-832. [CrossRef]

14. Kidd, S.A.; Shaw, D.A.; Janssen, H.A. Exploring land-sea interactions: Insights for shaping territorial space. Eur. XXI 2019, 36, 45-59. [CrossRef]

15. Allmendinger, P.; Haughton, G. Soft spaces, fuzzy boundaries, and meta governance. Environ. Plan. A 2009, 41, 617-633. [CrossRef]

16. Jay, S. The shifting sea: From soft space to lively space. J. Environ. Policy Plan. 2018, 20, 450-467. [CrossRef]

17. Jerzak, K.; Shrayer, M.D.A.; Krośnicka, K.A.; Lorens, P.; Zaucha, J.; Pardus, J. The essence of marine and coastal space-An interdisciplinary perspective. Eur. XXI 2019, 36, 15-34. [CrossRef]

18. Hull, A.D. Managing competition for marine space using the tools of planning in the UK. Plan. Pract. Res. 2013, 28, 503-526. [CrossRef]

19. Kidd, S.A.; Ellis, G. From the Land to Sea and Back Again? Using Terrestrial Planning to Understand the Process of Marine Spatial Planning. J. Environ. Policy Plan. 2012, 14, 49-66. [CrossRef]

20. Jay, S. From disunited sectors to disjointed segments? Questioning the functional zoning of the sea. Plan. Theory Pract. 2013, 14, 509-525. [CrossRef]

21. Jay, S. Marine space. Manoeuvring towards a relational understandings. J. Environ. Policy Plan. 2012, 14, 86-96. [CrossRef]

22. Tafon, R.; Howarth, D.; Griggs, S. The politics of Estonia's offshore wind energy programme: Discourse, power and marine spatial planning. Environ. Plan. C Politics Space 2018, 37, 157-176. [CrossRef]

23. Harley, J.B. Deconstructing the map. Cartographica 1989, 26, 1-20. [CrossRef]

24. Smith, G.; Brennan, R.E. Losing our way with mapping: Thinking critically about marine spatial planning in Scotland. Ocean Coast. Manag. 2012, 69, 210-216. [CrossRef]

25. Gee, K. The ocean perspective. In Maritime Spatial Planning, Past, Present and Future; Zaucha, J., Gee, K., Eds.; Palgrave Macmillan: Cham, Switzerland, 2019; pp. 23-45.

26. Paasi, A. The institutionalization of regions: A theoretical framework for understanding the emergence of regions and the constitution of regional identity. Fennia-Int. J. Geogr. 1986, 164, 105-146. [CrossRef]

27. Gee, K.; Kannen, A.; Adlam, R.; Brooks, C.; Chapman, M.; Cormier, R.; Fischer, C.; Fletcher, S.; Gubbins, M.; Shucksmith, R.; et al Identifying culturally significant areas for marine spatial planning. Ocean Coast. Manag. 2017, 136, 139-147. [CrossRef]

28. Piwowarczyk, J.; Gee, K.; Gilek, M.; Hassler, B.; Luttmann, A.; Maack, L.; Matczak, M.; Morf, A.; Saunders, F.; Stalmokaite, I.; et al. Insights into integration challenges in the Baltic Sea Region marine spatial planning: Implications for the HELCOM-VASAB principles. Ocean Coast. Manag. 2019, 175, 98-109. [CrossRef]

29. Shucksmith, R.; Gray, L.; Christina, K.; Tweddle, J.F. Regional marine spatial planning-The data collection and mapping process Marine Policy 2014, 50, 1-9. [CrossRef]

30. Lehtimäki, M.; Tevali, R.; Tikkanen, S. To Transmit Maritime Cultural Heritage Knowledge to Maritime Spatial Planning Processes; BalticRIM Status Report WP 2 GoA 2.1; Finnish Heritage Agency: Helsinki, Finland, 2020.

31. McKinley, E.; Acott, T.; Stojanovic, T. Socio-cultural dimension of marine spatial planning. In Maritime Spatial Planning, Past, Present and Future; Zaucha, J., Gee, K., Eds.; Palgrave Macmillan: Cham, Switzerland, 2019; pp. 151-174.

32. Martin, K.S.; Olson, J. Creating space for community in marine conservation and management: Mapping 'communities at sea'. In Conservation in the Anthropocene Ocean; Levin, P., Poe, M., Eds.; Elsevier: Amsterdam, The Netherlands, 2017 ; pp. 123-141.

33. Council of Europe. The European Landscape Convention; Council of Europe: Strasbourg, France, 2000.

34. Kosmatopoulos, N. On the shores of politics: Sea, solidarity and the ships to Gaza. Environ. Plan. D Soc. Space 2019, 37, 740-757. [CrossRef]

35. Printsmann, A.; Pikner, T. The Role of Culture in the Self-Organisation of Coastal Fishers Sustaining Coastal Landscapes: A Case Study in Estonia. Sustainability 2019, 11, 3951. [CrossRef]

36. Domon, G. Landscape as resource: Consequences, challenges and opportunities for rural development. Landsc. Urban Plan. 2011, 100, 338-340. [CrossRef]

37. Vihervaara, P.; Viinikka, A.; Brander, L.; Santos-Martín, F.; Poikolainen, L.; Nedkov, S. Methodological interlinkages for mapping ecosystem services-From data to analysis and decision-support. One Ecosyst. 2019, 4, e26368. [CrossRef]

38. IPBES. The Methodological Assessment Report on Scenarios and Models of Biodiversity and Ecosystem Services; Ferrier, S., Ninan, K.N., Leadley, P., Alkemade, R., Acosta, L.A., Akçakaya, H.R., Brotons, L., Cheung, W.W.L., Christensen, V., Harhash, K.A., et al., Eds.; Secretariat of the Intergovernmental Science-Policy Platform on Biodiversity and Ecosystem Services: Bonn, Germany, 2016; 348p. 
39. Ministry of Finance. Eesti Merealade Planeering. Seletuskiri [Estonian Maritime Spatial Plan. Explanatory Memorandum]; Version 10.07.2020, for Last Public Discussion; Ministry of Finance: Tallinn, Estonia; Hendrikon \& Ko: Tallinn, Estonia, 2020.

40. Kutsar, R. Eesti Merealade Planeering. Mõjude Hindamise Aruande Eelnõu Avalikule Väljapanekule [Estonian Maritime Spatial Plan. The Proposal of Impact Assessment for Public Discussion]; Version 03.07.2020; Hendrikson \& Ko: Tallinn, Estonia, 2020.

41. Sepp, K. The Estonian Green Belt; Seep, K., Ed.; Estonian University of Life Sciences: Tartu, Estonia, 2011.

42. Leisure Spaces. Holidays and Architecture in 20th Century Estonia; Lankots, E., Ojari, T., Eds.; Eesti Arhitektuurimuuseum: Tallinn, Estonia, 2020.

43. Nugin, R.; Palang, H. Borderscapes in landscape: Identity meets ideology. Theory Psychol. 2020, 31, 780-796. [CrossRef]

44. Printsmann, A.; Nugin, R.; Palang, H. Intricacies of moral geographies of land restitution in Estonia. Land 2022, 11, 235. [CrossRef]

45. Kase, K. Eesti Kohalike Omavalitsuste Huvid Mereala Ruumilisel Planeerimisel [The Interests of Estonian Local Municipalities in Martime Spatial Planning]. Master's Thesis, Estonian Life Science University, Tartu, Estonia, 2019.

46. Ministry of Environmental Protection and Regional Development. The Maritime Spatial Plan for the Marine Inland Waters, Territorial Sea and Exclusive Economic Zone Waters of the Republic of Latvia. National Level Long-Term Spatial Development Planning Document; Ministry of Environmental Protection and Regional Development: Riga, Latvia, 2019.

47. Ministry of Environmental Protection and Regional Development. The National Long Term Thematic Plan for Development of the Coastal Public Infrastructure; Ministry of Environmental Protection and Regional Development: Riga, Latvia, 2016.

48. Veidemane, K.; Ruskule, A.; Strake, S.; Purina, I.; Aigars, J.; Sprukta, S.; Ustups, D.; Putnis, I.; Klepers, A. Application of the marine ecosystem services approach in the development of the maritime spatial plan of Latvia. Int. J. Biodivers. Sci. Ecosyst. Serv. Manag. 2017, 13, 398-411. [CrossRef]

49. Leiper, N. Tourism attraction system. Ann. Tour. Res. 1990, 77, 367-384. [CrossRef]

50. Ruskule, A.; Klepers, A.; Veidemane, K. Mapping and assessment of cultural ecosystem services of Latvian coastal areas. One Ecosyst. 2018, 3, e25499. [CrossRef]

51. Brown, G.; Hausner, V.H. An empirical analysis of cultural ecosystem values in coastal landscapes. Ocean. Coast. Manag. 2017, 142, 49-60. [CrossRef]

52. Hazeu, G.; Metzger, M.; Mucher, S.; Perez-Soba, M.; Renetzeder, C.; Andersen, E. European environmental stratifications and typologies: An overview. Agric. Ecosyst. Environ. 2011, 142, 29-39. [CrossRef]

53. Müller, F.; De Groot, R.; Willemen, L. Ecosystem Services at the Landscape Scale: The Need for Integrative Approaches. Landsc. Online 2010, 23, 1-11. [CrossRef]

54. Sowińska-Świerkosz, B.N.; Chmielewski, T.J. A new approach to the identification of Landscape Quality Objectives (LQOs) as a set of indicators. J. Environ. Manag. 2016, 184, 596-608. [CrossRef] [PubMed]

55. Martínez-Harms, M.J.; Balvanera, P. Methods for mapping ecosystem service supply: A review. Int. J. Biodivers. Sci. Ecosyst. Serv. Manag. 2012, 8, 17-25. [CrossRef]

56. Scholte, S.S.; Daams, M.; Farjon, H.; Sijtsma, F.J.; van Teeffelen, A.J.; Verburg, P.H. Mapping recreation as an ecosystem service: Considering scale, interregional differences and the influence of physical attributes. Landsc. Urban Plan. 2018, 175, 149-160. [CrossRef]

57. Piwowarczyk, J.; Wróbel, B. Determinants of legitimate governance of marine Natura 2000 sites in a post-transition European Union country: A case study of Puck Bay, Poland. Mar. Policy 2016, 71, 310-317. [CrossRef]

58. Gee, K.; Siedschlag, D. A place-based perspective on marine and coastal space. Eur. XXI 2019, 36, 59-74. [CrossRef]

59. Zaucha, J. Offshore Spatial Information-Maritime Spatial Planning in Poland. Reg. Stud. 2012, 46, 459-473. [CrossRef]

60. Piwowarczyk, J.; Matczak, M.; Rakowski, M.; Zaucha, J. Challenges for integration of the Polish fishing sector into marine spatial planning (MSP): Do fishers and planners tell the same story? Ocean. Coast. Manag. 2019, 181, 104917. [CrossRef]

61. Peters, K.; Steinberg, P.; Stratford, E. Territory Beyond Terra; Rowman and Littlefield: London, UK, 2018.

62. Nassauer, J.I. Care and stewardship: From home to planet. Landsc. Urban Plan. 2011, 100, 321-323. [CrossRef]

63. Enquist, J.P. Stewardship as a boundary object for sustainability research: Linking care, knowledge and agency. Landsc. Urban Plan. 2018, 179, 17-37.

64. Ehler, C.; Zaucha, J.; Gee, K. Maritime/Marine Spatial Planning at the Interface of Research and Practice. In Maritime Spatial Planning, Past, Present and Future; Zaucha, J., Gee, K., Eds.; Palgrave Macmillan: Cham, Switzerland, 2019; pp. 1-22. [CrossRef] 